\title{
Control of the Simian Fetal Hemoglobin Switch at the
}

\section{Progenitor Cell Level}

\author{
Blanche P. Alter, Benjamin T. Jackson, Jeffrey M. Lipton, George J. Piasecki, \\ Pamela L. Jackson, Michele Kudisch, and David G. Nathan, Division of \\ Hematology and Oncology of the Children's Hospital Medical Center and the \\ Sidney Farber Cancer Institute, Department of Pediatrics, Harvard \\ Medical School, Boston, Massachusetts 02115; Department of Surgery, Boston \\ University Medical Center and Boston Veteran's Administration Medical Center, \\ Boston University School of Medicine, Boston, Massachusetts 02118; Polly \\ Annenberg Levee Hematology Center, Departments of Medicine and Pediatrics, \\ Mount Sinai School of Medicine, New York 10029
}

\begin{abstract}
A B S T RAC T This investigation was designed to define the cellular level at which the gamma to beta globin switch is established in the developing simian fetus in order to determine whether the switch is controlled by environmental influences within differentiating erythroid precursors or predetermined by the genetic program of erythroid progenitors. Samples of marrow and liver were obtained from rhesus fetuses throughout the switch period, and marrow was obtained from adult rhesus monkeys. Globin chain synthesis was then measured in differentiated erythroblasts and in erythroid progenitor-derived colonies grown in semisolid media. The relative rates of synthesis of gamma and beta chains were determined by the uptake of $\left[{ }^{3} \mathrm{H}\right]-$ leucine into the respective chains separated by Triton gel electrophoresis and in some cases by urea carboxymethyl cellulose chromatography. Four periods of the switch were defined during fetal development. In the preswitch period both erythroblasts and progenitor-derived colonies produced $<5 \%$ beta globin. In the early switch erythroblasts produced $5-15 \%$ beta globin, while progenitor-derived colonies produced $10-35 \%$ beta globin. In mid-switch erythroblasts synthesized
\end{abstract}

This material has been published in abstract form. Blood. 54: $62 \mathrm{a}, 1979$.

Dr. Jackson and G. Piasecki's current address is Veteran's Administration Medical Center, Davis Park, Providence, R. I. Address reprint requests to Dr. Alter, Division of Hematology, Mount Sinai School of Medicine. Dr. Alter is the recipient of National Institutes of Health Research Career Development Award HL 00177/00684, and an Irma T. Hirschl Career Scientist Award. Dr. Lipton is a Dyson Foundation Investigator in Pediatric Oncology.

Received for publication 3 July 1980 and in revised form 7 October 1980.
$50 \%$ beta globin, whereas progenitor-derived colonies produced only $15-35 \%$ beta. At the completion of the switch erythroblasts produced $100 \%$ beta globin, while progenitor-derived colonies produced as little as $40 \%$ beta chains. We conclude that the program of globin synthesis that characterizes the fetal switch is established at the level of erythroid progenitors. Fetal erythroid burst-forming units (BFU-E) dominate the marrow prior to the switch. The early switch period is heralded by the appearance of adult erythroid burstforming units programmed to express increasing beta chain synthesis in colonies. By mid-switch a second class of adult erythroid progenitors capable of giving rise to fetal and adult hemoglobin synthesis in in vitro colonies becomes apparent. These shifting populations of erythroid progenitors with unique globin synthesis programs give rise to the erythroblasts that create the sigmoid pattern of the fetal to adult hemoglobin switch in the developing simian fetus.

\section{INTRODUCTION}

One of the characteristics of normal human ontogeny is an orderly switch in the relative rates of expression of the gamma and beta globin genes. At 16-20 wk gestation, gamma chain synthesis represents $\sim 90 \%$ of total non-alpha chains (1). At birth the contribution of gamma genes is reduced to $\sim 60 \%$ of the total non-alpha synthesis (2). In normal adults hemoglobin $\mathrm{F}$ is $<2 \%$ of the total hemoglobin (3).

Molecular and cellular control of this fetal to adult switch has been a subject of intense investigation not only because of its importance as a model of gene regulation, but also for its clinical relevance. Inhibition of 
the switch could ameliorate diseases, such as sickle cell and Cooley's anemia.

The study reported here was designed to determine the hematopoietic cell level at which commitment to the switch from gamma to beta gene expression is established during ontogeny. This has been a matter of controversy. For example, the relative ratios of gamma and beta gene expression are influenced in culture by the state of maturity of erythroid precursors $(4,5) .{ }^{1}$ They are also said to be influenced by manipulation of the conditions in which erythroid precursors are incubated $(6,7)$. The above findings suggest that commitment to particular non-alpha globin gene expression occurs at a relatively late and morphologically identifiable stage of erythroid differentiation. On the other hand, the complexity of gamma, delta, and beta gene regulation implies that such fundamental decisions might be made at the level of erythroid progenitors and; that the process of ontogeny must be accompanied by an orderly progression of CFU-S-derived BFU-E endowed with increasing capacity to express the outputs of beta rather than gamma genes. Such a preprogrammed process would probably be independent of environmental or pharmacological manipulations other than those that interfere with the entire process of ontogeny and parturition (8).

The cellular level at which commitment of beta globin gene expression is established has been investigated in several laboratories in which human, simian, and caprian systems have been explored with varying interpretations of the results $(8-17,18)$. The experimental design presented here was strongly influenced by our perception that the potential role of progenitors in the gamma to beta switch program could only be established if we examined a model system that embraced the entire switch period in a species with definable beta and gamma expression and in colonies derived from early and late progenitors as well as precursor cells. Therefore, we studied planned pregnancies in rhesus monkeys (Macaca mulatta) and examined the gamma to beta switch in the erythroid progenitorderived colonies and in the differentiated erythroid precursors in adults and developing fetuses of that species.

\footnotetext{
${ }^{1}$ In this paper the term erythroid precursor refers to the stages of recognizable nucleated erythroid cells from pro to orthochromatic erythroblasts. The term erythroid progenitor inclusively describes the several classes of morphologically indistinguishable derivatives of trilineage colony forming units (CFU-S) that are committed to formation of erythroid precursors. The most primitive erythroid progenitor is an erythroid burst forming unit (BFU-E). The most mature is the erythroid colony forming unit (CFU-E). The identification and enumeration of these progenitors is necessarily indirect, based largely on the configuration and rate of appearance of the colonies to which they give rise in vitro.
}

\section{METHODS}

Animals. Rhesus monkeys (Macaca mulatta) were housed at the New England Regional Primate Research Center in Southborough, Mass. All procedures were approved by the scientific advisory committee at the Center. Normal adult monkeys were anesthetized with phencyclidine hydrochloride (Sernylan, Parke-Davis, Morris Plains; N. J.) $1 \mathrm{mg} / \mathrm{kg}$, administered intramuscularly. $20 \mathrm{ml}$ of blood was drawn from the antecubital vein, and added to $1 \mathrm{ml}$ of alpha medium lacking nucleosides (Gibco Laboratories, Grand Island Biological Co., Grand Island, N. Y.) containing $100 \mathrm{U}$ of heparin. Bone marrow was aspirated from the posterior iliac crest. Less than $0.5 \mathrm{ml}$ was aspirated at each time, and multiple aspirates were added to $5 \mathrm{ml}$ of alpha medium with heparin.

Pregnancies of specific gestational ages were obtained by mating an ovulatory female with a male for 3-5 $\mathrm{d}$. The pregnant female was tranquilized with phencyclidine, and then given $1 \mathrm{mg} / \mathrm{kg}$ succinyl choline intravenously, intubated, and anesthetized with halothane and oxygen. The fetus was delivered by caesarean section. 5-20 ml of umbilical cord blood was added to $1 \mathrm{ml}$ of alpha medium with $100 \mathrm{U}$ of heparin. The long bones were removed surgically, the ends cut off, and bone marrow cells flushed out with an 18-gauge needle on a $20-\mathrm{ml}$ syringe, using $15 \mathrm{ml}$ of alpha medium. The liver was removed and placed in $50 \mathrm{ml}$ of cold alpha medium. The gallbladder was dissected away, and the liver was minced with scissors. The liver was then dissociated into single cells using $\mathrm{Ca}^{++}$- and $\mathrm{Mg}^{++}$-free Hanks' balanced salt solution (Gibco Laboratories) containing $1 \mathrm{mM}$ EGTA (Ethyleneglycol-bis [beta-aminoethylether] $N, N^{\prime}$-tetraacetic acid) according to the procedure of Schwartz et al. (19). The cells were suspended in $25 \mathrm{ml}$ of alpha medium and large chunks removed by settling for $2 \mathrm{~min}$. The liver cell suspension was then centrifuged on Ficoll-Hypaque (Pharmacia Fine Chemicals, Uppsala, Sweden) to separate the hepatocytes (bottom layer) from the nucleated hematopoietic cells (interface layer). Packed erythrocytes were suspended 1:1 in alpha medium, and blood, bone marrow, and liver were all centrifuged on FicollHypaque at $400 \mathrm{~g}$ for $30 \mathrm{~min}$ at $18^{\circ} \mathrm{C}$. The interface cells were washed in alpha medium, counted, and resuspended in alpha medium at 10 times the final concentration.

Cell culture. Mononuclear cells were plated at 1-2 $\times 10^{6}$ cells per $\mathrm{ml}$ (blood) or $3-5 \times 10^{5}$ cells $/ \mathrm{ml}$ (marrow and liver) in the plasma clot culture system described elsewhere $(20-22)$. The erythropoietin used came from several sources, including human urinary erythropoietin, lots H-34-TaLSL, ARG-8 TaLSL, ARG-378-TaLSL, M-7-TaLSL, H36-TaLSL, kindly provided by Dr. Anne Ball, National Institutes of Health; and anemic sheep plasma erythropoietin (Connaught Medical Research Laboratories, Willowdale, Ontario, Canada, step III, lots 3022-3, 3030-1, 3026-1, 3026-4, 3025-1, 3029-1).

Clot volumes were $0.1 \mathrm{ml}$ for morphologic studies. Three clots of $0.3 \mathrm{ml}$ were used for biosynthetic studies. Erythropoietin was usually $2 \mathrm{U} / \mathrm{ml}$. For labeling newly synthesized proteins a $0.03-\mathrm{ml}$ volume containing $15 \mu \mathrm{Ci}$ of $\left[{ }^{3} \mathrm{H}\right]$ leucine (New England Nuclear, Boston, Mass., $>100 \mathrm{Ci} / \mathrm{mmol}$ ) was overlayed on each $0.3 \mathrm{ml}$ clot $(23)$. The $\left[{ }^{3} \mathrm{H}\right]$ leucine was prepared by mixing $1 \mathrm{vol}$ of $\left[{ }^{3} \mathrm{H}\right]$ leucine in $0.01 \mathrm{~N} \mathrm{HCl}$ with $1 \mathrm{vol}$ of NCTC-109 (Microbiological Associates, Walkersville, Md.) and neutralizing with 0.01 vol of $1 \mathrm{~N} \mathrm{NaOH}$. Labeling was for 16-20 h, beginning $1 \mathrm{~d}$ before harvesting. Cultures were incubated in high humidity, with $5 \% \mathrm{CO}_{2}$, for 2-3 d for CFU-Ederived colonies and for 5-6 d for BFU-E-derived colonies.

The cells were recovered from the plasma clots by treatment with Pronase (22). Three 0.3- $\mathrm{ml}$ clots were pooled and $3 \mathrm{ml}$ of a solution of Pronase (Calbiochem-Behring Corp., American Hoechst Corp., San Diego, Calif.), $1 \mathrm{mg} / \mathrm{ml}$ in $0.9 \% \mathrm{NaCl}$ was 
added. The clots were dissociated by gentle agitation. Cold serum was added to stop the reaction, and the tubes centrifuged at $4^{\circ} \mathrm{C}$ for $5 \mathrm{~min}$ at $500 \mathrm{~g}$. The cells were washed twice with cold $0.9 \% \mathrm{NaCl}$, and then lysed for 1 min with $30 \mu \mathrm{l}$ of cold deionized water containing $0.1 \%$ Triton X-100. Stroma were removed by centrifugation at $1,200 \mathrm{~g}$ for $10 \mathrm{~min}$ at $4^{\circ} \mathrm{C}$. The lysates were stored at $-80^{\circ} \mathrm{C}$.

Globin analysis. Aliquots of blood, bone marrow, and liver cells were removed prior to the Ficoll-Hypaque centrifugation, washed with Krebs-Ringer's-phosphate solution and incubated with $\left[{ }^{3} \mathrm{H}\right]$ leucine for $2 \mathrm{~h}$ at $37^{\circ} \mathrm{C}$ as described previously (24). This was to label newly synthesized globin chains produced by peripheral blood reticulocytes, or by bone marrow or liver erythroblasts. Globin chain synthesis patterns were determined in two ways. First, samples with low specific activities were treated with acidified acetone to precipitate globin chains. The globins were then separated by chromatography on carboxymethyl cellulose CM-52 columns. The elution buffer consisted of $8 \mathrm{M}$ urea with a nonlinear gradient of sodium phosphate, provided with an LKB Ultrograd 11300 gradient forming device (LKB Produkter, Bromma, Sweden). The starting buffer was $3.5 \mathrm{mM}, \mathrm{pH} 6.75$, and the finishing buffer $35 \mathrm{mM}, \mathrm{pH} 6.75$. This method is similar to a system used to separate human globin chains (24).

In most studies, globin chains were separated by electrophoresis on polyacrylamide gels, as described by Rovera et al. (25) and modified by Alter et al. (26). Radioactive lysates, plus unlabeled carrier fetal and adult monkey hemoglobin when indicated, were electrophoresed on 11-cm slab gels. The gels contained $12 \%$ acrylamide, $0.08 \%$ bis-acrylamide, $6 \mathrm{M}$ urea, $5 \%$ acetic acid, and $2 \%$ Triton X-100. Preelectrophoresis was for $1 \mathrm{~h}$ at $200 \mathrm{~V}$ followed by a second preelectrophoresis with $1 \mathrm{M}$ cystamine for $45 \mathrm{~min}$ at $150 \mathrm{~V}$. The samples were dissolved in $6 \mathrm{M}$ urea, $5 \%$ acetic acid, $0.8 \mathrm{M}$ mercaptoethanol, and electrophoresed for $17 \mathrm{~h}$ at $8 \mathrm{~mA}$. The gels were stained for $30 \mathrm{~min}$ with $0.5 \%$ Coomassie blue in $30 \%$ methanol, $7 \%$ acetic acid, and then destained in methanol-acetic acid by diffusion. The gels were then treated with dimethylsulfoxide and PPO, for fluorography (27), using preflashed Kodak X-Omat R film (28). The film was developed in a Kodak X-Omat (Eastman Kodak Co., Rochester, N. Y.). The fluorograms were scanned at 615 $\mathrm{nm}$ in a Gilford 2400 or 240 spectrophotometer with a linear transport mechanism (Gilford Instrument Laboratories, Inc., Oberlin, Ohio). The time of exposure of the films was sufficient to produce an absorbance of between 2.0 and 3.0 in the highest peak (the alpha chain). The areas under the peaks were determined by drawing a base line connecting the lowest points surrounding each peak. Globin bands were identified by their coelectrophoresis with unlabeled carrier globins, and their alignment with radiolabeled control fetal and adult globin chains in the same slab gel. The gel data were used to calculate the percent beta synthesis $[\beta /(\beta+\gamma) \times 100]$ and the percent gamma $2\left[\gamma_{2} /\left(\gamma_{1}+\gamma_{2}\right) \times 100\right]$. Globin chain synthesis was compared in marrow erythroblasts, CFU-E-derived colonies, and BFU-E-derived colonies.

The globin chain composition of the blood of animals of various ages was determined by electrophoresis of $30 \mu \mathrm{g}$ of hemoglobin on a $6.0 \times 14-\mathrm{cm}$ disc gel for $18 \mathrm{~h}$ at $100 \mathrm{~V}$. These gels were stained for $24 \mathrm{~h}$ with $0.05 \%$ Coomassie blue in $30 \%$ methanol, $7 \%$ acetic acid, and destained by diffusion. The stained proteins were quantitated by scanning at $550 \mathrm{~nm}$ in the Gilford as above.

Cellular distribution of $\mathrm{HbF}$. A single newborn monkey was studied at serial intervals during infancy. Peripheral blood was obtained by toe prick or venipuncture. Cover slip smears were made, fixed with $80 \%$ ethanol, and the acid elution test of Kleihauer et al. (29) performed using a kit from Boehringer-Mannheim Biochemicals, Indianapolis, Ind.

\section{RESULTS}

\section{Determination of globin chain synthesis in precursors}

\section{ERYTHROCYTE GLOBIN ACCUMULATION}

Fig. 1 shows a typical electrophoretic separation of the three major globin chains in the peripheral erythrocytes of a developing fetus and the two major chains of an adult rhesus monkey. The basis of gamma chain heterogeneity in the rhesus is not due to glycine/alanine variability at position 136 , as is the case in humans $(30,31)$.

Fig. 2 shows the time-course of the switch from $100 \%$ fetal to $100 \%$ adult globin in the rhesus. Note that only $\sim 30 \%$ of fetal globin is replaced by adult globin at parturition.

Fig. 3 demonstrates the cellular distribution of fetal hemoglobin in a 22-d-old rhesus infant. Most of the cells are darkly stained because they contain a large proportion of $\mathrm{HbF}$. However, in contrast to previously published claims (32) many are clearly intermediate in intensity, and some are "ghosts" that had contained only adult hemoglobin. These ghosts were observed as early as $8 \mathrm{~d}$ after birth. With the passage of time, the proportions of intermediate cells and then of ghosts increased to replace the cells that had contained $\mathrm{HbF}$ as the predominant hemoglobin. The latter comprise $<5 \%$ of the total population by $100 \mathrm{~d}$ of age.

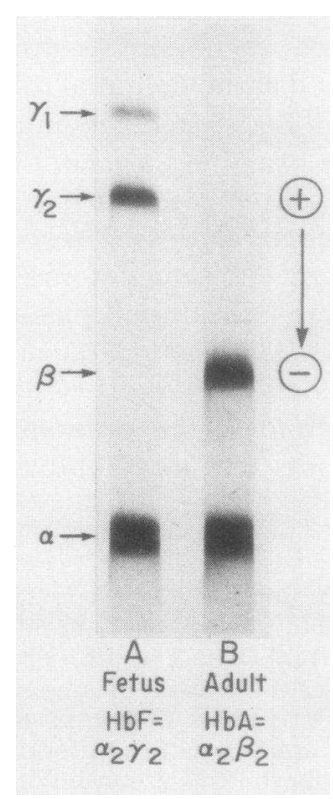

FIGURE 1 Triton gel electrophoresis of globin chains in blood from rhesus monkeys. Gels were stained with Coomassie blue. (A) 103-d-old fetus- $\gamma_{1^{-}}, \gamma_{2^{-}}$, and $\alpha$-globin chains are seen. (B) Adult $-\beta$ - and $\alpha$-globin chains are seen. 


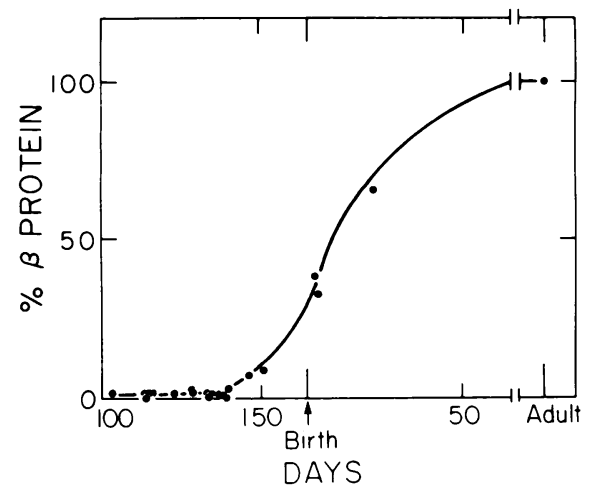

Figure 2 Time-course of the switch from $\gamma$ to $\beta$ globin in the rhesus monkey. Term birth is at $165 \mathrm{~d}$. Percent $\beta$-globin protein in erythrocytes was measured on Coomassie blue-stained Triton polyacrylamide disc gels.

\section{GLOBIN CHAIN BIOSYNTHESIS}

Marrow precursors and reticulocytes. Fig. 4 shows the time-course of the switch from gamma to beta globin chain synthesis in the peripheral blood reticulocytes and marrow erythroblasts of developing rhesus fetuses. The curves are very similar in shape, the reticulocyte curve being displaced somewhat to the right consonant with the estimated marrow transit time of differentiating precursors. As expected, gamma chain synthesis is predominant in the fetus and absent in the adult. The switch is virtually complete at birth and the shape of the

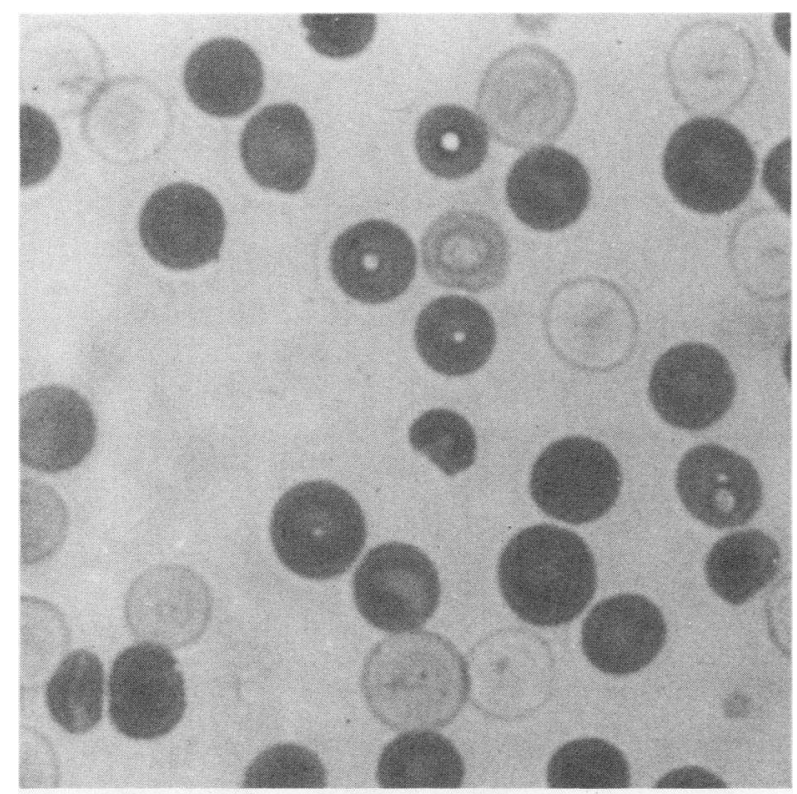

FIGURE 3 Acid elution preparation of blood from a 22-d-old rhesus monkey fetus. Dark cells contained predominantly fetal hemoglobin. Clear "ghosts" contained only adult hemoglobin. Gray intermediate cells contained both fetal and adult hemoglobin.

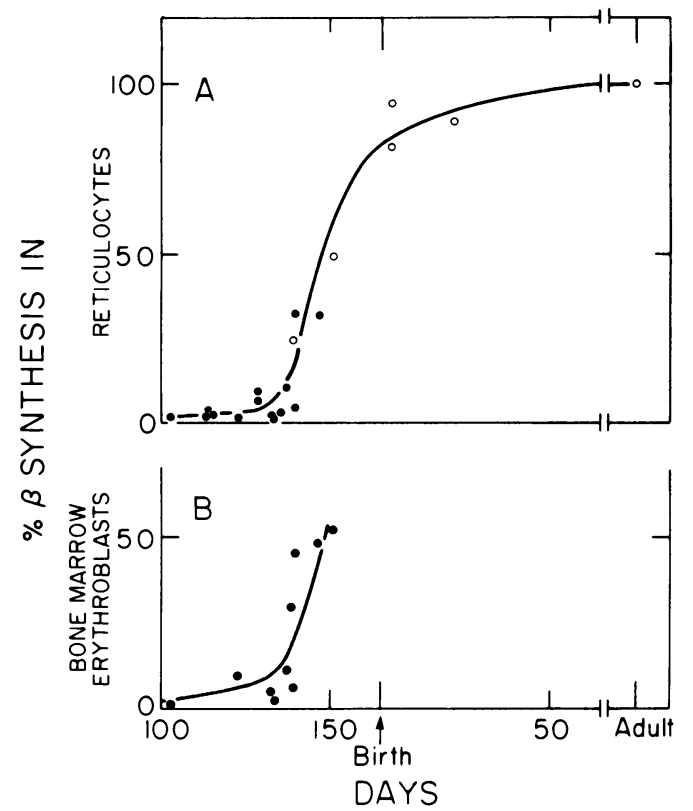

Figure 4 Time-course of the biosynthetic switch from $\gamma$ - to $\beta$-globin in the rhesus monkey. (A) Percent $\beta$-globin synthesis by peripheral blood reticulocytes, measured on fluorograms of $\left[{ }^{3} \mathrm{H}\right]$ leucine labeled globins, separated by electrophoresis on Triton polyacrylamide slab gels $(\mathbf{O})$, or by carboxymethylcellulose chromatography (O). (B) Percent $\beta$-globin synthesis by bone marrow erythroblasts, measured as in $A$.

curve can be roughly divided into segments which we refer to as pre $(<5 \% \beta)$, early $(5-15 \% \beta)$, mid $(40-60 \%$ $\beta$ ), and late or post $(>85 \% \beta)$ switch periods (Table I).

Globin synthesis ratios in the reticulocytes and marrow precursors of fetuses, neonates, and adults are shown in Table I. The fetal data are grouped into early and mid-switch periods determined from the percent $\beta$ globin synthesis in bone marrow erythroblasts and not from gestational age. The alpha/non-alpha ratio was balanced in all of the studies (data not shown) and the gamma-2 fraction of total gamma globin synthesis did not change during fetal development.

\section{Progenitor-derived colonies}

\section{ERYTHROID COLONY FREQUENCY AND MORPHOLOGY IN ADULTS AND FÉTUSES}

Erythroid colonies appeared in cultures of the mononuclear cells from adult bone marrow, but not from peripheral blood. The appearance of the colonies was entirely dependent on the presence of erythropoietin.

Numerous erythroid colonies emerged in cultures of mononuclear cells from fetal bone marrow and liver. Their morphology is shown in Fig. 5. On days 2-3 there were 500-1,000 CFU-E-derived colonies per $10^{5}$ mononuclear cells plated even in the absence of added erythropoietin, and more than 2,000 CFU-E-derived 
TABLE I

Globin Synthesis in Rhesus Monkeys during Ontogeny

\begin{tabular}{|c|c|c|c|c|c|}
\hline \multirow{2}{*}{$\begin{array}{l}\text { Switch } \\
\text { period }\end{array}$} & \multirow[b]{2}{*}{ Gestation } & \multicolumn{2}{|c|}{$\begin{array}{l}\text { Reticulo- } \\
\text { cytes }\end{array}$} & \multicolumn{2}{|c|}{$\begin{array}{c}\text { Bone } \\
\text { marrow }\end{array}$} \\
\hline & & $\beta$ & $\dot{\gamma}_{2}$ & $\beta$ & $\gamma_{2}$ \\
\hline & $d$ & \multicolumn{2}{|c|}{$\%$} & \multicolumn{2}{|c|}{$\%$} \\
\hline \multirow{3}{*}{ Pre } & 103 & $<5$ & 69 & $<5$ & 78 \\
\hline & 133 & $<5$ & 75 & $<5$ & 70 \\
\hline & 134 & $<5$ & 70 & $<5$ & 74 \\
\hline \multirow[t]{3}{*}{ Early } & 123 & $<5$ & 61 & 9 & 70 \\
\hline & 137 & 10 & 65 & 12 & 72 \\
\hline & 140 & $<5$ & 71 & 5 & 72 \\
\hline \multirow[t]{3}{*}{ Mid } & 140 & 32 & 70 & 46 & 74 \\
\hline & 147 & 30 & 81 & 49 & 81 \\
\hline & 151 & 48 & 68 & 53 & 78 \\
\hline \multirow[t]{3}{*}{ Infants* } & $3 \mathrm{~d}$ & 89 & 75 & - & - \\
\hline & $3 \mathrm{~d}$ & 94 & 78 & - & - \\
\hline & $3 \mathrm{wk}$ & 81 & 74 & - & - \\
\hline \multicolumn{2}{|l|}{$\begin{array}{r}\text { Adults* }(5 \\
\text { animals) }\end{array}$} & 100 & - & 100 & - \\
\hline
\end{tabular}

Globin synthesis measured by gel electrophoresis or *carboxymethyl cellulose chromatography.

colonies per $10^{5}$ marrow cells when $0.1,0.5$, or $2 \mathrm{U}$ of erythropoietin were added to each milliliter of clot. The appearance of BFU-E-derived colonies at 5-6 d was more dependent on added erythropoietin. Only $\sim 10$

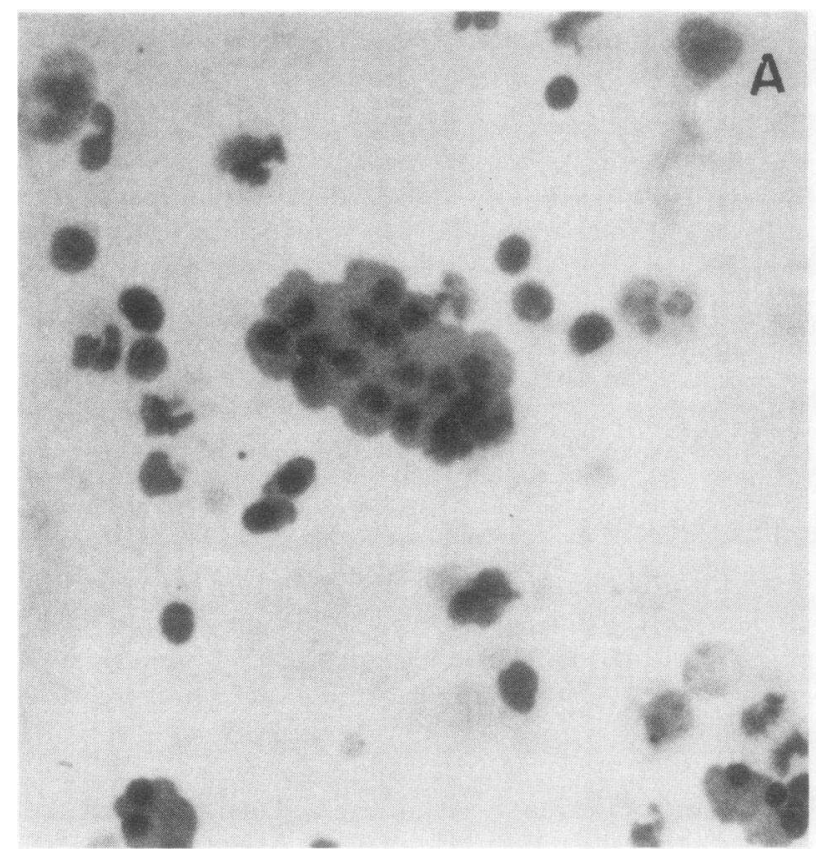

BFU-E-derived colonies per $10^{5}$ marrow cells appeared in the absence of added erythropoietin but $\sim 100$ of these colonies per $10^{5}$ cells appeared when $0.1,0.5$, and $2 \mathrm{U}$ of erythropoietin per milliliter was added to cultures.

The frequency of erythroid progenitors was higher in the marrows of younger fetuses and was identical in the livers and marrows of fetuses $<140 \mathrm{~d}$ gestation. After $140 \mathrm{~d}$, liver progenitor frequency markedly declined.

\section{GLOBIN CHAIN BIOSYNTHESIS IN ADULT ERYTHROID PROGENITOR-DERIVED COLONIES}

Representative fluorograms of the electrophoretically separated labeled globin chains derived from the erythroblasts and erythroid colonies of an adult monkey are shown in Fig. 6A. There was no gamma chain synthesis in the erythroblasts. In contrast, radioactivity was prominent in the gamma-1 and gamma-2 regions of the globin chain electrophoreses prepared from CFU-Eand BFU-E-derived colonies. The high background in some lanes was due to nonglobin proteins, synthesized by cells in nonerythroid colonies, particularly in adult specimens. Total gamma chain synthesis was $29 \%$ in the CFU-E and as high as $66 \%$ in the BFU-E-derived colonies in this experiment. Four such studies are summarized in Table II. Gamma chain synthesis was absent in all of the erythroblast samples, but was easily detectable in all of the progenitor-derived colonies.

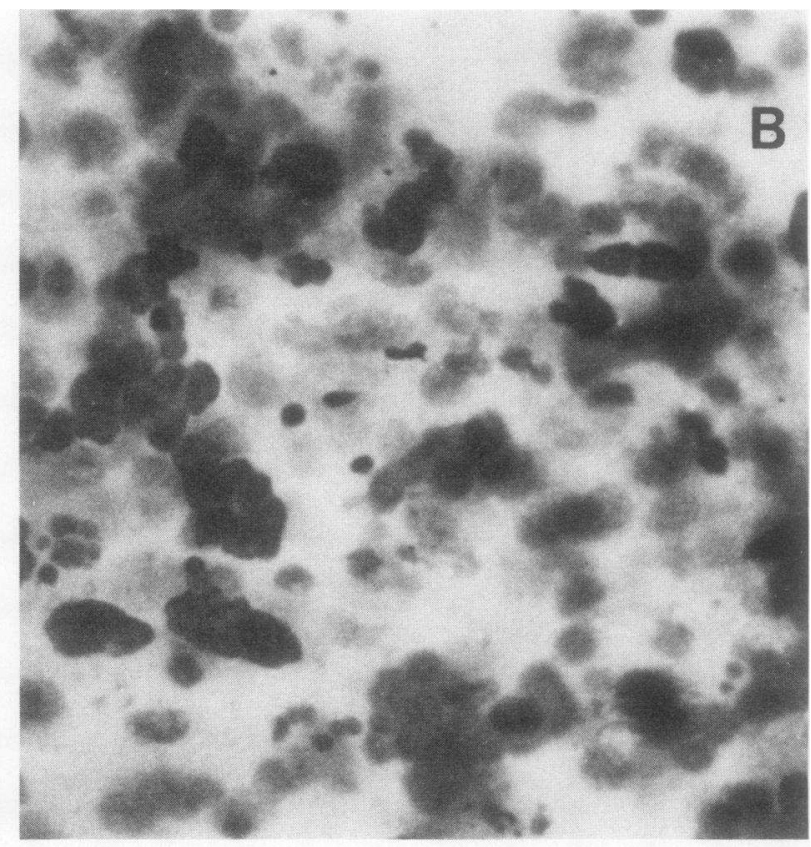

FIGURE 5 Erythroid colonies derived from a 140-d-old fetal rhesus monkey. (A) CFU-E, day 3.

(B) BFU-E, day 6. 


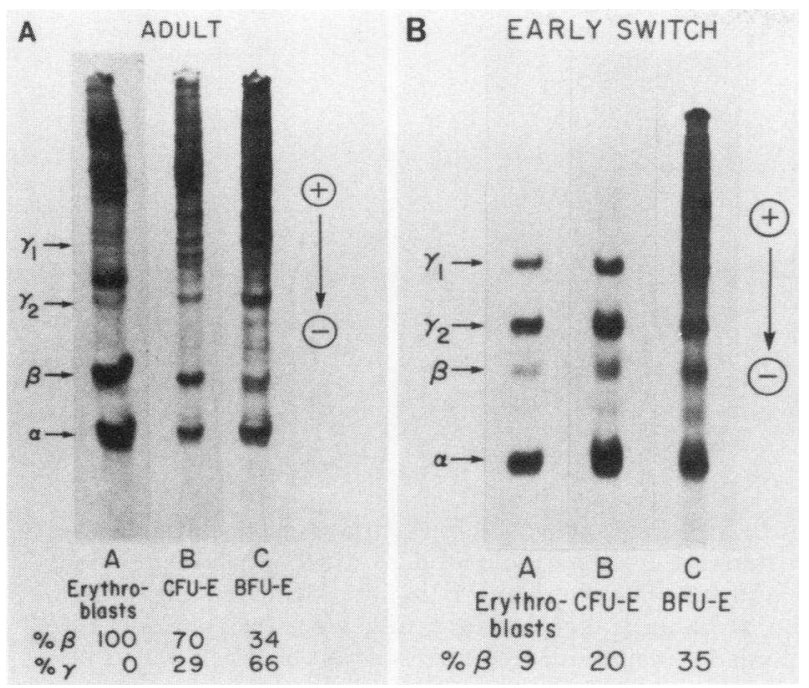

FIGURE 6 Fluorograms of gel electrophoretic separation of $\left[{ }^{3} \mathrm{H}\right]$ leucine-labeled globin chains. (A) rhesus monkey adult. (B) 123-d-old rhesus monkey fetus. (A) Bone marrow erythroblasts, day 0. (B) CFU-E-derived colonies, day 3. (C) BFU-Ederived colonies, day 6 .

\section{GLOBIN CHAIN BIOSYNTHESIS IN FETAL ERYTHROID PROGENITOR-DERIVED COLONIES}

Fig. 6B provides an example of a determination of globin chain synthesis in fetal erythroid precursors and erythroid progenitor-derived colonies in the early switch period. Beta globin synthesis was just detectable $(9 \%)$ in precursors but was prominent in progenitor-derived colonies, particularly those derived from BFU-E.

The results of a series of such studies carried out during the pre, early, and mid-switch periods are set out in Table III. The data show that beta globin synthesis
TABLE II

Globin Synthesis in Precursors and Progenitor-derived Colonies from Rhesus Monkey Adult Bone Marrow

\begin{tabular}{|c|c|c|c|c|c|}
\hline \multicolumn{4}{|c|}{ Percentage $\gamma$ synthesis } & \multirow{2}{*}{\multicolumn{2}{|c|}{$\gamma_{2}$ as percentage of $\gamma$}} \\
\hline & Enothro & & & & \\
\hline Study & blasts & CFU-E & BFU-E & CFU-E & BFU-E \\
\hline Male 1 & $\mathbf{0}$ & 64 & 58 & 41 & 52 \\
\hline Male $1^{*}$ & $\mathbf{0}$ & 29 & 66 & 59 & 55 \\
\hline Male 2 & 0 & 13 & 45 & 50 & 68 \\
\hline Female 1 & 0 & 24 & 36 & 52 & 73 \\
\hline Mean \pm 1 SD & 0 & $28 \pm 17$ & $48 \pm 13$ & $51 \pm 1$ & $65 \pm 10$ \\
\hline
\end{tabular}

* Second study was performed 4 mo after the first.

was negligible in erythroblasts and colonies of the preswitch period. In two of three studies performed during the early switch period the percent beta chain synthesis in progenitor-derived colonies substantially exceeded that detected in erythroid precursors, and BFU-Ederived colonies were particularly striking in this regard.

The findings at mid-switch were paradoxical. The relationship of progenitor-derived colony beta chain synthesis to precursor beta chain synthesis had become completely reversed. The colonies (particularly those derived from BFU-E) exhibited considerably lower beta chain synthesis than did the erythroblasts. Similar findings were noted in single studies of mid-switch in a caprian model system by Darbre and her associates (17) and a baboon system by DeSimone and his coworkers (15).

\section{THE OUTPUT OF THE GAMMA GENES}

The ratio of gamma-2 to total gamma chain synthesis remained quite constant in all of the studies of fetal

TABLE III

Globin Synthesis in Precursors and Progenitor-Derived Colonies from Fetal Rhesus Monkey Bone Marrow

\begin{tabular}{|c|c|c|c|c|c|c|c|c|c|}
\hline \multirow[b]{2}{*}{$\begin{array}{l}\text { Switch } \\
\text { period }\end{array}$} & \multirow[b]{2}{*}{ Gestation } & \multirow[b]{2}{*}{ Hemoglobin } & \multirow[b]{2}{*}{ Reticulocytes } & \multicolumn{3}{|c|}{ Percent $\beta$ synthesis } & \multicolumn{3}{|c|}{$\gamma_{2}$ as percentage of $\gamma$} \\
\hline & & & & $\begin{array}{l}\text { Erythro- } \\
\text { blasts }\end{array}$ & CFU-E & BFU-E & $\begin{array}{l}\text { Erythro- } \\
\text { blasts }\end{array}$ & CFU-E & BFU-E \\
\hline & $d$ & g/dl & $\%$ & & & & & & \\
\hline \multirow[t]{3}{*}{ Pre } & 103 & 14 & 7.4 & $<5$ & $<5$ & - & 73 & 76 & - \\
\hline & 133 & 13 & 3.1 & $<5$ & $<5$ & 5 & 70 & 67 & 75 \\
\hline & 134 & 12 & 3.4 & $<5$ & $<5$ & - & 74 & 69 & - \\
\hline \multirow[t]{3}{*}{ Early } & 123 & 12 & 3.1 & 9 & 20 & 35 & 70 & 71 & 63 \\
\hline & 137 & 14 & 4.1 & 12 & 17 & 13 & 72 & 76 & 64 \\
\hline & 140 & 13 & 2.0 & 5 & 9 & 35 & 72 & 65 & 77 \\
\hline \multirow[t]{3}{*}{ Mid } & 140 & 13 & 2.3 & 46 & 31 & 26 & 74 & 64 & 72 \\
\hline & 147 & 12 & 2.3 & 49 & 16 & 18 & 80 & 78 & 72 \\
\hline & 151 & 12 & 1.1 & 53 & 35 & 20 & 78 & 72 & 73 \\
\hline
\end{tabular}


progenitor-derived colonies but comparison of Table III with Table II shows that the ratio tended to be lower in adult progenitor derived colonies than in either the erythroblasts or progenitor-derived colonies of fetuses. It should be emphasized that quantitation of that ratio was rendered somewhat imprecise by the close proximity of nonglobin chains to the gamma areas of the electrophoretic gels. That the contaminating bands on the gels shown here were derived from nonerythroid cells was established by the fact that they appeared in gels from cultures of adult marrow to which no erythropoietin had been added and no erythroid colonies had developed. Furthermore, they did not appear in gels in which labeled reticulocyte proteins were separated.

Not shown in the tables is the fact that an increase in the concentration of erythropoietin in the cultures over a 20-fold range from 0.1 to $2 \mathrm{U} / \mathrm{ml}$ did not influence either the percent beta or the percent gamma-2 in the erythroid colonies.

\section{DISCUSSION}

The study reported here was designed to determine whether the program of the gamma to beta globin switch in the developing simian fetus could be indirectly detected in fetal erythroid progenitors prior to its detection in the differentiated erythroid precursors to which the progenitors ultimately give rise. Similar inquiries have been previously launched by other investigators who have utilized aborted human fetal samples as well as human cord blood cells for this purpose (9-14). Such human studies cannot be directly compared to the simian system. First, the human pre-switch period is characterized by somewhat higher beta chain synthesis in precursors. Beta chain synthesis in the erythroid precursors of human fetuses as early as $84 \mathrm{~d}$ gestation ranges from 7 to $10 \%$ (1). Second, the human switch occurs over a considerably longer time-course than does the simian switch. In fact, the midpoint of the human switch is not even attained at the time of birth. Thus human abortuses provide pre-switch samples and cord bloods offer early and accelerating switch samples.

Despite these differences the data in Fig. 7, which represent a compilation of human studies in which relevant progenitor and precursor analyses were performed, agree with our findings in the simian pre- and early switch samples. In the human pre-switch period, the percent beta synthesis in progenitors and precursors is generally equal with perhaps a slight weight toward beta synthesis in progenitors. During the early and accelerated switch, the progenitor-derived colonies (particularly the BFU-E-derived colonies) exhibit considerably more relative beta synthesis than the differentiated precursors can summon. The erythroblasts become endowed with the non-alpha chain program detected in their progenitors several days before.

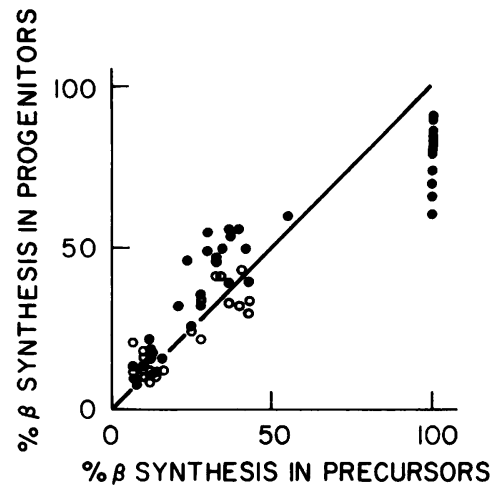

Figure 7 Percent beta globin synthesis in erythroid progenitor-derived colonies compared to differentiated precursors, in humans. The solid line is hypothetical. It represents the line of identity that would result, were progenitor-derived colonies to maintain percentages of beta chain synthesis identical to those detected in simultaneously acquired marrow erythroid precursors. O, CFU-E-derived colonies. $9, \mathrm{BFU}-\mathrm{E}-$ derived colonies. Data are from references 10, 11, 14, 23, 35, and 41.

Data in humans at mid-switch are not available because the acquisition of such information would require marrow aspirates or large blood samples from healthy infants. Study of this period demands a simian model. There the observed data are unexpected and apparently paradoxical. Fig. 8 provides a summary of our simian switch data. In the early switch period progenitorderived (particularly BFU-E-derived) colonies exhibit higher percent beta chain synthesis than do the differentiated precursors obtained in the same sample. But at mid-switch the reverse is true. The progenitor-derived colonies, particularly those that arise from BFU-E, exhibit much lower percent beta chain synthesis than do the precursors. These results qualitatively resemble those derived from studies of adult monkeys (Fig. 8).

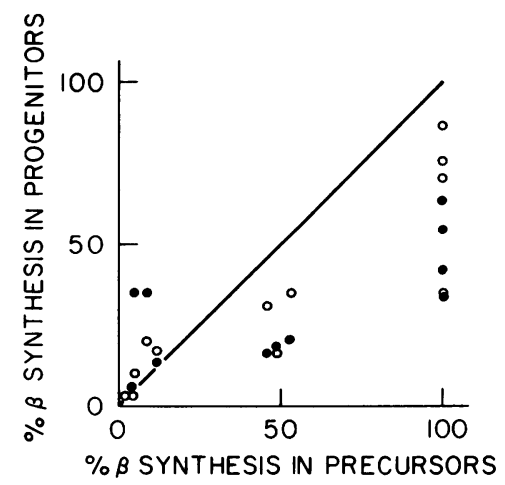

FIGURE 8 Percent beta globin synthesis in erythroid progenitor-derived colonies compared with differentiated precursors, in rhesus monkeys. See legend to Fig. 7. 
Fetal hemoglobin is not normally detected in adult simian marrow erythroblasts or circulating erythrocytes. However, the marrow BFU-E- and CFU-Ederived colonies of normal adult rhesus monkeys and baboons contain cells that produce gamma chains. Adult baboons rendered anemic or anoxic rapidly produce erythrocytes that contain high levels of fetal hemoglobin $(15,33)$. Thus erythroid progenitors capable of expression of gamma genes in the erythroid cells to which they give rise are present in normal adult animals and probably contribute to the profusion of $\mathrm{F}$ cells that emerge in the blood during stress erythropoiesis.

In man, as well, adult marrow precursors normally produce only tiny amounts of fetal hemoglobin but progenitor-derived colonies that produce $\mathrm{HbF}$ are detected in variable proportions in human marrows $(23,34-38)$. More importantly, the frequency of such progenitorderived colonies increases in chronic anemic states $(23$, $34,35,37$, conditions in which $F$ erythrocytes are detected in increased frequency in the peripheral blood $(39,40)$.

These studies of adult simian and human erythropoiesis suggest that certain erythroid progenitors capable of giving rise to erythroblasts that synthesize both $\mathrm{HbF}$ and $\mathrm{HbA}$ exist in variable frequencies in adult marrow. We call these progenitors $\mathrm{BFU}-\mathrm{E}_{\mathrm{FA}}$. Their presence helps to explain our findings in fetal simian marrow at mid-switch. Fetal BFU-E (BFU-E $\left.E_{F}\right)$ dominate the marrow and hepatic erythroid progenitor pools in the pre-switch period. These progenitors or their programs are then progressively replaced by progenitors, the globin gene program of which is characterized by a rising ratio of beta to gamma chain synthesis. At mid-switch, the contribution of BFU- $E_{F A}$ becomes apparent and persists into adult life. These may actually be the progenitors of the $\mathrm{F}$ erythrocytes that accumulate during anemic stress.

This study of the fetal-adult switch in the simian system shows that the ratio of beta to gamma globin synthesis to be expressed in precursors in the fetal marrow is apparently determined at the level of progenitor cells that are endowed with changing programs of globin gene expression. Isolation of these progenitors and the colonies that they produce will provide more detailed understanding of switch kinetics and perhaps useful approaches to switch manipulation.

\section{ACKNOWLEDGMENTS}

We are grateful to the staff at the New England Regional Primate Research Center for their cooperation and assistance. We acknowledge the excellent technical assistance of Paul MacGarvey and Joan Luthy.

This work was supported by National Institutes of Health grants HD 11471, HL 07146, AM 15322, CA 18662, CA 19589 and by a grant from the Amy Clare Potter Memorial Fund, Children's Hospital Medical Center, Boston.

\section{REFERENCES}

1. Cividalli, G., D. G. Nathan, Y. W. Kan, B. Santamarina, and F. Frigoletto. 1974. Relation of beta to gamma synthesis during the first trimester: an approach to prenatal diagnosis of thalassemia. Pediatr. Res. 8: 553-560.

2. Alter, B. P. 1978. Beta-thalassemia trait: imprecision of diagnosis at birth. Br. J. Haematol. 38: 323-327.

3. Singer, K., A. I. Chernoff, and L. Singer. 1951. Studies on abnormal hemoglobins. I. Their demonstration in sickle cell anemia and other hematologic disorders by means of alkali denaturation. Blood. 6: 413-428.

4. Papayannopoulou, Th., T. Kalmantis, and G. Stamatoyannopoulos. 1979. Cellular regulation of hemoglobin switching: evidence for inverse relationship between fetal hemoglobin synthesis and degree of maturity of human erythroid cells. Proc. Natl. Acad. Sci. U. S. A. 76: 6420-6424.

5. Dover, G. J., and S. H. Boyer. 1980. Quantitation of hemoglobins within individual red cells: asynchronous biosynthesis of fetal and adult hemoglobin during erythroid maturation in normal subjects. Blood. 56: $1082-1091$.

6. Thomas, E. D., H. L. Lochte, Jr., W. B. Greenough, III, and M. Wales. 1960 . In vitro synthesis of foetal and adult haemoglobin by foetal hematopoietic tissues. Nature (Lond.). 135: 396-397.

7. Allen, D. W., and J. H. Jandl. 1960. Factors influencing relative rates of synthesis of adult and fetal hemoglobin in vitro. J. Clin. Invest. 38, 1107-1113.

8. Wood, W. G., K. Pearce, J. B. Clegg, J. S. Robinson, G. D. Thorburn, and G. S. Dawes. 1976. Switch from foetal to adult haemoglobin synthesis in normal and hypophysectomised sheep. Nature (Lond.). 264: 799-800.

9. Rowley, P. T., B. Ohlsson-Wilhelm, B. A. Farley, and B. Kosciolek. 1979. Hemoglobin synthesis in cultures of hepatic erythroid cells from the human fetus. Proc. Natl. Acad. Sci. U. S. A. 76: 1477-1481.

10. Hassan, M. W., A. Ibrahim, R. F. Rieder, and L. L. Cederqvist. 1979. Synthesis of $\mathrm{HbA}$ and $\mathrm{HbF}$ in erythroid colonies cultured from human fetal liver and umbilical cord blood. Blood. 54: 1140-1151.

11. Stamatoyannopoulos, G., B. B. Rosenblum, Th. Papayannopoulou, M. Brice, B. Nakamoto, and T. H. Shepard. 1979. $\mathrm{HbF}$ and $\mathrm{HbA}$ production in erythroid cultures from human fetuses and neonates. Blood. 54: 440-450.

12. Kidoguchi, K., M. Ogawa, J. D. Karam, J. M. Wilson, and M. S. Fitch. 1978. Synthesis of fetal and adult hemoglobins in culture by human umbilical cord blood erythropoietic precursors. Hemoglobin. 2: 503-512.

13. Comi, P., B. Giglioni, S. Ottolenghi, A. M. Gianni, E. Polli, P. Barba, A. Covelli, G. Migliaccio, M. Condorelli, and C. Peschle. 1980. Globin chain synthesis in single erythroid bursts from cord blood: studies on $\gamma \rightarrow \beta$ and ${ }^{\mathrm{G}} \gamma \rightarrow{ }^{\mathrm{A}} \gamma$ switches. Proc. Natl. Acad. Sci. U. S. A. 77: $362-365$.

14. Beuzard, Y., W. Vainchenker, U. Testa, A. Dubart, N. Monplaisir, J. Breton-Gorius, J. Rosa, J. Bouguet, J. Cacheleux, and P. Rouyer-Fessard. 1979. Fetal to adult hemoglobin switch in cultures of early erythroid precursors from human fetuses and neonates. Am. J. Hematol. 7: 207-218.

15. DeSimone, J., P. Heller, and J. G. Adams. 1979. Hemopoietic stress and fetal hemoglobin synthesis: comparative studies in vivo and in vitro. Blood. 54: 1176-1181.

16. Barker, J. E., J. E. Pierce, B. C. Kefauver, and A. W. Nienhuis. 1977. Hemoglobin switching in sheep and 
goats: induction of hemoglobin $\mathrm{C}$ synthesis in cultures of sheep fetal erythroid cells. Proc. Natl. Acad. Sci. U. S. A. 74: 5078-5082.

17. Darbre, P. D., J. W. Adamson, W. G. Wood, D. J. Weatherall, and J. S. Robinson. 1979. Patterns of globin chain synthesis in erythroid colonies grown from sheep marrow of different development stages. Br. J. Haematol. 41: 459-475.

18. Barker, J. E. 1980. Hemoglobin switching in sheep: characteristics of BFU-E-derived colonies from fetal liver. Blood. 56: 495-500.

19. Schwartz, A. L., R. Schwartz, and H. C. Schwartz. 1976. Effect of hypoxia in erythroblasts from avian fetal liver: adenosine triphosphate levels and hemoglobin synthesis. Pediatr. Res. 10: 796-801.

20. Nathan, D. G., B. J. Clarke, D. G. Hillman, B. P. Alter, and D. E. Housman. 1978. Erythroid precursors in congenital hypoplastic (Diamond-Blackfan) anemia. J. Clin. Invest. 61: 489-498.

21. McLeod, D. L., M. M. Shreeve, and A. A. Axelrad. 1974. Improved plasma culture system for production of erythrocytic colonies in vitro: quantitative assay method for CFU-E. Blood. 44: 517-534.

22. Clarke, B. J., and D. Housman. 1977. Characterization of an erythroid precursor cell of high proliferative capacity in normal human peripheral blood. Proc. Natl. Acad. Sci. U. S. A. 74: 1105-1109.

23. Clarke, B. J., D. G. Nathan, B. P. Alter, B. G. Forget, D. G. Hillman, and D. Housman. 1979. Hemoglobin synthesis in human BFU-E and CFU-E derived erythroid colonies. Blood. 54: 805-817.

24. Alter, B. P., C. B. Modell, D. Fairweather, J. C. Hobbins, M. J. Mahoney, F. D. Frigoletto, A. S. Sherman, and D. G. Nathan. 1976. Prenatal diagnosis of hemoglobinopathies. N. Engl. J. Med. 295: 1437-1443.

25. Rovera, G., C. Magarian, and T. W. Borun. 1978. Resolution of hemoglobin subunits by electrophoresis in acid urea polyacrylamide gels containing Triton X-100. Anal. Biochem. 85: 506-518.

26. Alter, B. P., S. C. Goff, G. D. Efremov, M. E. Gravely, and T. H. J. Huisman. 1980. Globin chain electrophoresis: a new approach to the determination of the ${ }^{\mathrm{G}} \boldsymbol{\gamma} /{ }^{\mathrm{A}} \boldsymbol{\gamma}$ ratio in fetal haemoglobin and to studies of globin synthesis. $\mathrm{Br}$. J. Haematol. 44: 527-534.

27. Bonner, W. M., and R. A. Laskey. 1974. A film detection method for tritium-labelled proteins and nucleic acids in polyacrylamide gels. Eur. J. Biochem. 46: 83-88.

28. Laskey, R. A., and A. D. Mills. 1974. Quantitative film detection of ${ }^{3} \mathrm{H}$ and ${ }^{14} \mathrm{C}$ in polyacrylamide gels by fluorography. Eur. J. Biochem. 56: 335-341.

29. Kleihauer, E., H. Braun, and K. Betke. 1957. Demonstration von fetalem Hämoglobin in den Erythrocyten eines Blutausstrichs. Klin. Wochenschr. 35: 637-638.

30. Schroeder, W. A., T. H. J. Huisman, J. R. Shelton, J. B. Shelton, E. F. Kleihauer, A. M. Dozy, and B. Robberson.
1968. Evidence for multiple structural genes for the $\gamma$ chain of human fetal hemoglobin. Proc. Natl. Sci. U. S. A. 60: $537-544$.

31. Huisman, T. H. J., W. A. Schroeder, M. E. Keeling, N. Gengozian, A. Miller, A. R. Brodie, J. R. Shelton, J. B. Shelton, and G. Apell. 1973. Search for nonallelic structural genes for $\gamma$-chains of fetal hemoglobin in some primates. Biochem. Genet. 10: 309-318.

32. Wu, N-C, D. A. Sikkema, N. H. Altman, and R. M. Zucker. 1977. Identification of hemoglobins within individual rhesus monkey (Macaca mulatta) erythrocytes. Lab. Anim. Sci. 27: 986-992.

33. DeSimone, J., S. I. Biel, and P. Heller. 1978. Stimulation of fetal hemoglobin synthesis in baboons by hemolysis and hypoxia.Proc. Natl. Acad. Sci.U. S. A. 75: 2937-2940.

34. Papayannapoulou, Th., P. E. Nute, S. Kurachi, and G. Stamatoyannopoulos. 1978. Consistent activation of fetal hemoglobin synthesis in cultured adult bone marrow cells. Blood. 51: 671-679.

35. Kidoguchi, K., M. Ogawa, J. D. Karam, and A. G. Martin. 1978. Augmentation of fetal hemoglobin (HbF) synthesis in culture by human erythropoietic precursors in the marrow and peripheral blood: studies in sickle cell anemia and nonhemoglobinopathic adults. Blood. 52: 1115-1124.

36. Vainchenker, W., U. Testa, N. Hinard, Y. Beuzard, A Dubart, A. Tsapis, N. Monplaisir, P. Rouyer-Fessard, and J. Rosa. 1980. Hemoglobin synthesis in 7-day and 14-dayold erythroid colonies from the bone marrow of normal individuals. Hemoglobin. 4: 53-67.

37. Huisman, T. H. J., G. D. Efremov, A. L. Reese, J. S. Howard, M. E. Gravely, H. F. Harris, and J. B. Wilson. 1979. The synthesis of fetal hemoglobin types in red blood cells and in BFU-E derived colonies from peripheral blood of patients with sickle cell anemia, $\beta+-$ and $\delta \beta$ thalassemia, various forms of hereditary persistence of fetal hemoglobin normal adults and newborn. Hemoglobin. 3: 223-252.

38. Papayannopoulou, T., M. Brice, and G. Stamatoyannopoulos. 1977. Hemoglobin $F$ synthesis in vitro: evidence for control at the level of primitive erythroid stem cells. Proc. Natl. Acad. Sci. U. S. A. 74: 2923-2927.

39. Dover, G. J., S. H. Boyer, and W. H. Zinkham. 1979. Production of erythrocytes that contain fetal hemoglobin in anemia. Transient in vivo changes. J. Clin. Invest. 63: 173-176.

40. Papayannopoulou, T., E. Vichinsky, and G. Stamatoyannopoulos. 1980. Fetal $\mathrm{Hb}$ production during acute erythroid expansion. I. Observation in patients with transient erythroblastopenia and post-phlebotomy. Br.J. Haematol. 44: 535-546.

41. Papayannopoulou, T., B. Nakamoto, J. Buckley, S. Kurachi, P. E. Nute, and G. Stamatoyannopoulos. 1978. Erythroid progenitors circulating in the blood of adult individuals produce fetal hemoglobin in culture. Science (Wash. D. C.). 199: 1349-1350. 